\title{
Effect of intra-abdominal volume increment on lungs in hemorrhagic shock
}

\author{
Liu D, Tan H, Zhang L, Wang Z, Ge H, Zhang W, Sun S, Xiao H, Huang X \\ State Key Laboratory of Trauma, Burns and Combined Injury, Trauma Center, Institute of Surgery Research, \\ Daping Hospital, Third Military Medical University, Chongqing.dpzhangly@163.com
}

\begin{abstract}
Purpose: Intra-abdominal hypertension (IAH) causes lung dysfunction in patients after hemorrhagic shock resuscitation. We performed intra-abdominal volume increment (IAVI) to IAH and studied its effect on pulmonary function.

Methods: Eight minipigs established for IAH model by exsanquination until shock, incomplete blockage of portal vein and overload resuscitation were randomly divided into IAVI group $(n=4)$ and sham-operated control group $(n=4)$. Bladder pressure, arterial blood gas analysis and thoraco-abdominal computed tomography (CT) scans were measured. The minipigs were sacrificed $26 \mathrm{~h}$ after surgery, and lung samples were harvested for measuring the wet-to-dry weight ratio and hematoxylin-eosin staining.

Results: Compared with sham-operated control group, the respiratory rate and $\mathrm{paCO}_{2}$ remarkably decreased and $\mathrm{paO}_{2}$ notably increased at 8 and $12 \mathrm{~h}$ in the IAVI group. The bladder pressure also notably decreased at 8 , 12 , and $22 \mathrm{~h}$ after IAVI treatment. However, a significant improvement in diaphragm height was observed at 22 $\mathrm{h}$ after IAVI treatment. The wet-to-dry weight ratio of the lungs in IAVI group was also significantly higher than that that in the sham-operated control group.

Conclusions: Our data indicate that IAVI surgery could improve the damaged pulmonary function caused by IAH after hemorrhagic shock resuscitation (Tab. 1, Fig. 7, Ref. 21). Full Text in PDF www.elis.sk.

Key words: hemorrhagic shock, resuscitation, IAH, CT, intra-abdominal volume increment, lung, minipig.
\end{abstract}

According to guidelines of the World Society of the Abdominal Compartment Syndrome (WSACS), the abdominal compartment syndrome (ACS) is defined as an occurrence of intra-abdominal pressure (IAP) of $>20 \mathrm{mmHg}$, with or without abdominal perfusion pressure (APP) of $\leq 60 \mathrm{mmHg}$, and single or multiple organ system failure that was not previously present (1). The normal range of IAP is 0 to $7.5 \mathrm{mmHg}$. The WSACS defines intra-abdominal hypertension (IAH) as IAP of $\geq 12 \mathrm{mmHg}$ (2).

Generally speaking, a change in abdominal volume led to an increase in IAP. Malbrain et al. analyzed 97 patients admitted into 13 ICUs in 6 countries because of abdominal injury or other factors, and observed that the incidence of IAH and ACS was 50.5 $\%$ and $8.2 \%$, respectively; (3). One-third of the patients who had

State Key Laboratory of Trauma, Burns and Combined Injury, Trauma Center, Institute of Surgery Research, Daping Hospital, Third Military Medical University, Chongqing

Address for correspondence: Lian-yang Zhang, State Key Laboratory of Trauma, Burns and Combined Injury, Trauma Center, Institute of Surgery Research, Daping Hospital, Third Military Medical University, Chongqing, PR China 400042,

Phone: +86.13508308400 , Fax: +86.02368757991

Acknowledgements: This study was approved by the Third Military Medical University Council on Animal Care in accordance with the guidelines of the Ministry of Science and Technology of People's Republic of China (The Guidance of Experimental Animal Welfare, 2006).

The authors acknowledge support by the "Twelfth-Five-Year Scientific and Technological Supporting Plan of China” (2012BAI11B00) undergone serious general surgical operations developed IAH, and one-third of IAH patients eventually suffered from ACS (4). In the treatment of hemorrhagic shock, a large amount of resuscitation fluid is used to stabilize effective circulation. Shock often results in capillary leakage with much liquid penetrating into the third space, and may lead to intestinal edema and ascites, thus revoking an increase in IAP and even leading to IAH and ACS (5). Prevention of ACS decreases the incidence of multiple organ failure (MOF) (6).

The effect of increased IAP on lungs has been recognized for many years. IAP is transmitted to the chest directly or indirectly through the diaphragm, which can cause a decrease in total lung volume and oxygenation (7-9).

Intra-abdominal volume increment (IAVI) is also known as abdominal decompression surgery or damage control laparotomy (10). In this paper, IAVI is defined as the use of vacuum sealing in an abdominal incision to increase the abdominal volume and thus reduce IAH. Abdominal decompression or volume increment is an important method for the treatment of IAH or ACS (11); few reports have focused on their effects on lung function, particularly in large animals with physiological functions similar to those of humans.

In this study, we established an IAH model in minipigs that simulated perihepatic packing after clinical hemorrhagic shock from serious hepatic injury, fluid resuscitation, and IAH. In attempt to study the effect on lung function, we used IAVI assisted by vacuum sealing drainage to treat the IAH. 


\section{Materials and methods}

Animals

Twelvehealthy GuangxiBamaminipigs, either sex, weighing 22.9 $\pm 1.7 \mathrm{~kg}$ were provided by the Experimental Animal Center of Daping Hospital, Third Military Medical University, Chongqing, China.

\section{Reagents and instruments}

Saline $(0.9 \% \mathrm{NaCl}, 500 \mathrm{~mL}$; Sichuan Kelun Pharmaceutical Co., Ltd., Chengdu, China), Ringer's solution ( $\mathrm{NaCl} 0.85 \%, \mathrm{KCl}$ $0.03 \%, \mathrm{CaCl}_{2} 0.033$ \%, 500 mL; Sichuan Kelun Pharmaceutical Co., Ltd., Chengdu, China), KCl (10 mL:1 g; Wubei Tiansheng Kangdi Pharmaceutical Co., Ltd., Wuhan, China), ketamine (2 mL:0.1 g; Jiangsu Hengrui Medicine Co., Ltd., Lianyungang, China), pentobarbital sodium (25 g, P3761; Sigma-Aldrich, San Francisco, CA, USA), and iodine $(0.5 \%, 468 \mathrm{~mL}$; Jiangsu Aite $\mathrm{Fu}$, Jiangsu, China) were used in this study. The equipment used included blow-extruded double blood bags (Jiaxing Tianhe Pharmaceutical Co., Ltd., Zhejiang, China), single-lumen catheters (SWL-1996-01C-03-20; Sungwon, Korea), and disposable syringes ( $2 \mathrm{~mL}$; Beihua Medical Material Co., Ltd., Shenyang, China).

Instruments used included an anesthesia machine (SOUSAR; Beijing Yian Medical Inc., Beijing, China), multifunction monitor (M3046A; Hewlett-Packard, Palo Alto, CA, USA), Vigileo monitor (American Edwards Lifesciences Corporation, Irvine, CA, USA), blood gas analyzer (GEM Premier 3000; American Society for Testing Instruments, Irvine, CA, USA), and CT scanner (LightSpeed VCT, General Electric Company, NY, USA).

\section{IAH model of resuscitation after hemorrhagic shock}

Animals were fasted for $12 \mathrm{~h}$ before surgery with free access to water, and were anesthetized by posterior auricular vein injection of ketamine $(7.2 \mathrm{mg} /(\mathrm{h} \cdot \mathrm{kg}))$ and $3 \%$ sodium pentobarbital (6 $\mathrm{mg} /(\mathrm{h} \cdot \mathrm{kg}))$. After routine-sterilization, the animals were fixed on the experimental table and the skin was disinfected with iodophor. After tracheotomy, assisted respiration was performed through an anesthesia machine with pure oxygen inhalation. The right femoral artery and vein were isolated, and single-lumen catheters were in-

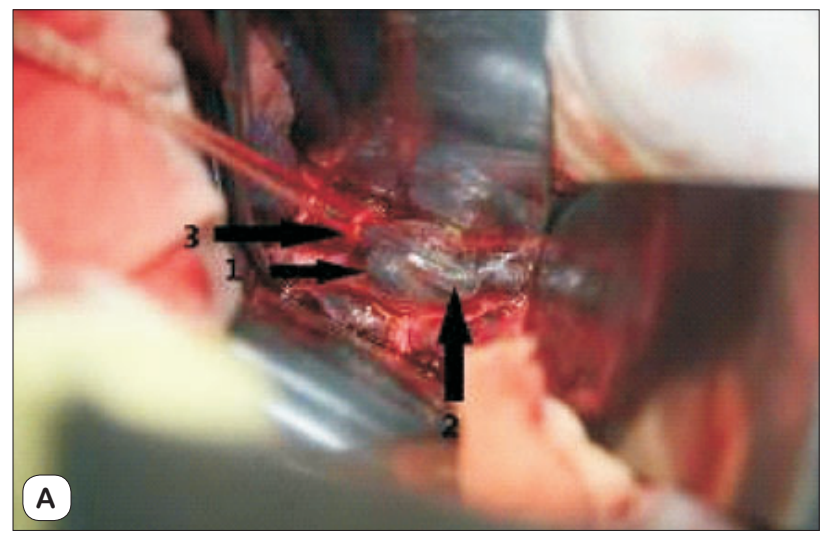

serted. A femoral artery tube was connected to the pressure sensor of the multifunctional monitor and blow-extruded double blood bags for preservation. A midline abdominal incision was made and cystostomy was performed. The portal vein was isolated and ligated with a hard plastic tube with an external diameter of $5 \mathrm{~mm}$ by using a thick string. The hard plastic tube was then removed, and a model of incomplete blockage of the portal vein was created to simulate the process of perihepatic packing for treatment of serious hepatic injury (Fig. 1A, B). The intravenous tube was used as a transfusion channel. Femoral artery exsanguination was performed till mean arterial pressure reached $50 \mathrm{mmHg}$, and the blood was stored in a blood bag. The abdominal wall incision was closed by layered sutures. Oxygen inhalation ( $4 \mathrm{~L} / \mathrm{min}, \mathrm{FiO}_{2} 37 \%$ ) was performed via a tracheotomy tube following the operation without assisted respiration. One hour after shock, all of the lost blood, along with Ringer's solution, was transfused. Ringer's solution was continuously administered to achieve over-resuscitation. The IAH model was considered successfully established when IAP of $\geq 12$ $\mathrm{mmHg}$ was maintained for $1 \mathrm{~h}$. Before successfully establishing the model (the amount of transfused Ringer's solution $1668.8 \pm 25.59$ $\mathrm{ml}, 76 \pm 3 \mathrm{ml} / \mathrm{h} \cdot \mathrm{kg}), 4$ animals died of hemorrhagic shock.

\section{Grouping and surgical procedures}

Animals that died before the successful establishment of model $(n=4)$ were excluded. When IAP reached the level of IAH, the remaining animals were divided randomly into the IAVI group $(n=4)$ and sham-operated control group $(n=4)$ by using a coin-toss method. In the IAVI group, the abdominal incision sutures were removed, and the incisions were extended from the xiphoid to the pubic symphysis. The ligatures of the portal vein were loosened and removed, and the omentum was flattened above the bowels. Based on the size of the incision, a polyvinyl alcohol gelatin foam sponge of approximately $30 \times 20 \mathrm{~cm}$ was placed along the incision and the full layer of abdominal wall was sutured. The drainage tube embedded in the sponge was extracted from one side of the incision. A biological permeable membrane with good permeability for oxygen and moisture was used to cover the incision and the sponge until it was sealed. Drainage tubes were used to maintain

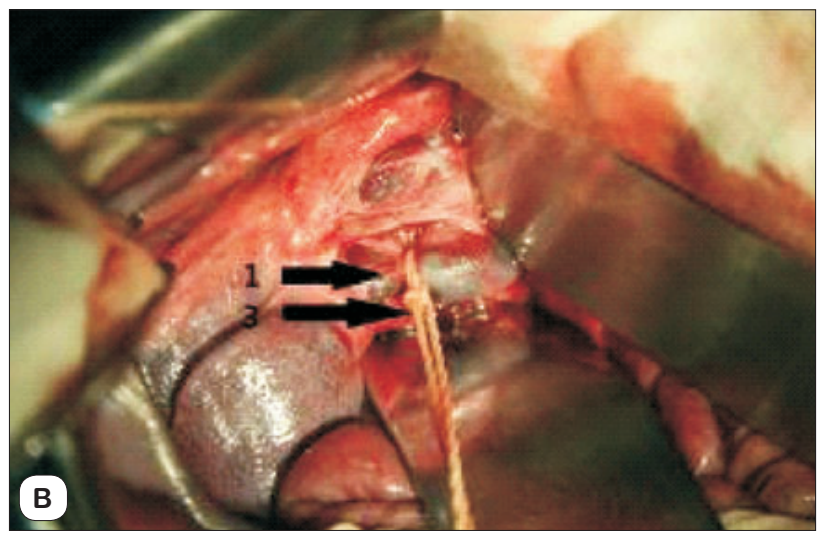

Fig. 1. Incomplete blockage of portal vein. (A) The portal vein (arrow 1) was ligated with hard plastic tube (arrow 2) with external diameter of $5 \mathrm{~mm}$ using a thick string (arrow 3). (B) The hard plastic tube was removed, achieving the model of incomplete blockage of the portal vein at a stable degree. 


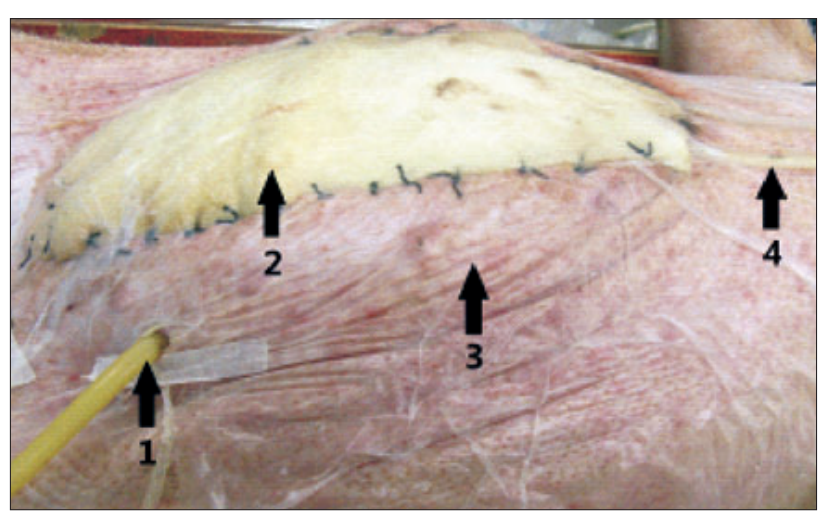

Fig. 2. Abdominal incision after IAVI treatment; arrow 1 refers to the bladder fistula tube; arrow 2 refers to a polyvinyl alcohol gelatin sponge; arrow 3 refers to a biological permeable sealing membrane with good permeability for oxygen and moisture; arrow 4 refers to drainage tubes in the foam with a negative pressure of 60 to $80 \mathrm{mmHg}$.

a negative pressure of 60 to $80 \mathrm{mmHg}$ with continuous suction until the animals were killed (Fig. 2) (12). In the sham-operated control group, the abdominal incision sutures were removed, the incisions were extended from the xiphoid to the pubic symphysis, and the ligature of the portal vein was loosened and removed. The incision was then directly closed by layered sutures.

\section{Measurement of urinary bladder pressure}

Bladder water manometry, which is recommended by WSACS, was used to measure IAP indirectly before shock; $1 \mathrm{~h}$ after shock; $2 \mathrm{~h}$ after IAH; and 8, 12, and $22 \mathrm{~h}$ after treatment. After complete evacuation of urine from the bladder, $50 \mathrm{~mL}$ of saline was instilled into the bladder (13-14). The vertical height of the water column above the symphysis pubis represented the bladder pressure, which was used to reflect the change in IAP.

\section{Blood gas analysis}

A total of $2 \mathrm{~mL}$ of arterial blood was drawn before shock, 1 $\mathrm{h}$ after shock, $2 \mathrm{~h}$ after IAH, and 8 and $12 \mathrm{~h}$ after treatment, respectively; for blood gas analysis $\left(\mathrm{paCO}_{2}\right.$ and $\left.\mathrm{paO}_{2}\right)$. Meanwhile, changes in the respiratory rate (RR) were measured.

\section{Computed tomography examination}

Computed tomography examination was performed before shock, $2 \mathrm{~h}$ after IAH, and $22 \mathrm{~h}$ after treatment. Animals were placed in a supine position to perform thoraco-abdominal enhanced CT scanning. The spinous process was marked for identifying the midsagittal-plane image to determine the height of the diaphragm. The mid-sagittal-plane image was analyzed as follows: the horizontal line along the superior border of the manubrium was drawn as the baseline, and the vertical distance between the highest point of the diaphragm and the baseline was recorded as a relative height of the diaphragm. CT Hounsfield units of the left lower lung lobe were measured, and the pleural effusion was observed.

Wet-to-dry ratio and pathological examination of the lung sample

Twenty-six hours after treatment, the animals were sacrificed by intravenous injection of $20 \mathrm{~mL} 10 \% \mathrm{KCl}$. Tissue samples were harvested from the left lung and weighed, then dried in a $60^{\circ} \mathrm{C}$ oven for 3 days before another weighing. The wet-to-dry ratio was calculated with the following equation: wet-to-dry ratio $=$ (wet weight - dry weight) / dry weight. The tissue samples from the right lung were stained by routine HE staining and observed under light microscope.

\section{Statistical analysis}

SPSS17.0 software was used for statistical analysis. Experimental data were expressed as mean $\pm \mathrm{SD}$. Analysis of variance of repeated measures in the general linear model was used for differences between groups, and one-way ANOVA was used for differences among inner-group times of our data. Differences were considered statistically significant when $\mathrm{p}<0.05$.

\section{Results}

\section{Changes in pulmonary function}

An increasing RR trend was observed during IAH model establishment, and RR was significantly increased at $2 \mathrm{~h}$ after IAH as compared with that before shock and $1 \mathrm{~h}$ after shock. RR showed a decrease at 8 and $12 \mathrm{~h}$ after IAVI, which was remarkable at $12 \mathrm{~h}$ after IAVI treatment $(\mathrm{p}<0.05)$. In the sham-operated control group, no notable improvement in the RR increase caused by IAH was observed. However, there was no significant difference at $8 \mathrm{~h}$ after IAVI treatment between the sham-operated control group and the IAVI group; there was only a significant difference at $12 \mathrm{~h}$ after IAVI treatment between the two groups $(\mathrm{p}<0.05)$.

An increasing $\mathrm{pCO}_{2}$ trend was observed during IAH model establishment, and $\mathrm{pCO}_{2}$ was significantly increased at $2 \mathrm{~h}$ after IAH as compared with that before shock and $1 \mathrm{~h}$ after shock. $\mathrm{pCO}_{2}$ showed a significant decrease at 8 and $12 \mathrm{~h}$ after IAVI $(\mathrm{p}<0.01)$, and there was no significant difference at 8 and $12 \mathrm{~h}$ after IAVI

Tab. 1. Changes in respiratory function in different groups after hemorrhagic shock resuscitation in minipigs (mean \pm SD).

\begin{tabular}{|c|c|c|c|c|c|c|}
\hline Indexes & Groups & $\begin{array}{l}\text { Before shock } \\
(n=8)\end{array}$ & $\begin{array}{c}1 \mathrm{~h} \text { after } \\
\text { shock }(\mathrm{n}=8)\end{array}$ & $\begin{array}{c}2 \mathrm{~h} \text { after } \\
\text { IAH }(\mathrm{n}=8)\end{array}$ & $\begin{array}{c}8 \mathrm{~h} \text { after } \\
\text { treatment }(\mathrm{n}=4)\end{array}$ & $\begin{array}{c}12 \mathrm{~h} \text { after } \\
\text { treatment }(\mathrm{n}=4)\end{array}$ \\
\hline \multirow{2}{*}{ RR (breaths/min) } & IAVI group & \multirow{2}{*}{$25.8 \pm 2.4$} & \multirow{2}{*}{$27.6 \pm 3.4$} & \multirow{2}{*}{$38.0 \pm 3.5 \S$} & $30.8 \pm 3.6^{\star}$ & $25.0 \pm 5.4^{\star} \triangle$ \\
\hline & sham-operated control group & & & & $34.5 \pm 4.0$ & $38.5 \pm 2.6$ \\
\hline \multirow{2}{*}{$\mathrm{PCO}_{2}(\mathrm{mmHg})$} & IAVI group & \multirow{2}{*}{$48.0 \pm 11.2$} & \multirow{2}{*}{$72.8 \pm 17.1$} & \multirow{2}{*}{$91.5 \pm 16.5 \S$} & $35.5 \pm 13.3^{\star} \triangle$ & $25.0 \pm 11.0^{\star} \triangle$ \\
\hline & sham-operated control group & & & & $82.8 \pm 3.5$ & $87.5 \pm 3.1$ \\
\hline \multirow{2}{*}{$\mathrm{PO}_{2}(\mathrm{mmHg})$} & IAVI group & \multirow{2}{*}{$396 \pm 72$} & \multirow{2}{*}{$331 \pm 44$} & \multirow{2}{*}{$297 \pm 23 \S$} & $389 \pm 43^{\star} \triangle$ & $378 \pm 87^{\star}$ \\
\hline & sham-operated control group & & & & $300 \pm 20$ & $314 \pm 12$ \\
\hline
\end{tabular}

Note: Compared with that before shock, $\S \mathrm{p}<0.05$. Compared with $2 \mathrm{~h}$ after IAH, ${ }^{\star} \mathrm{p}<0.05$. IAVI group vs. sham-operated control group, ${ }^{\triangle} \mathrm{p}<0.05$. 


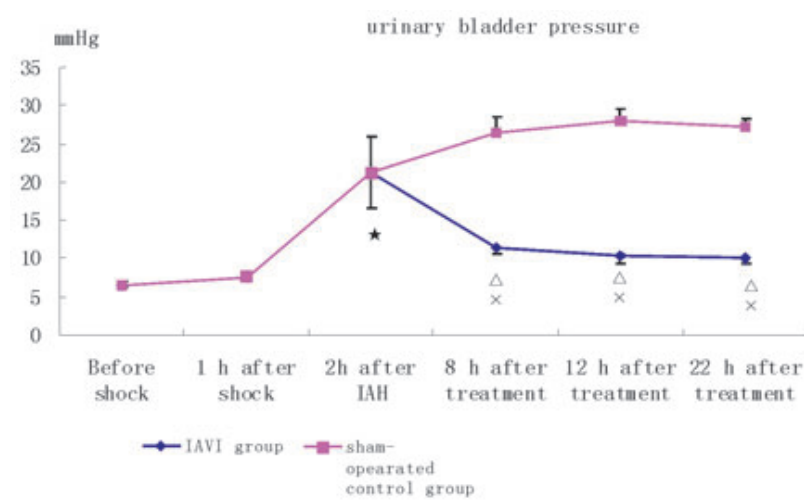

Fig. 3. Urinary bladder pressure (mean $\pm \mathrm{SD})$ in different groups induced by IAH after hemorrhagic shock resuscitation of minipigs. IAVI group $(n=4)$, sham-operated control group $(n=4)$. Compared before and $1 \mathrm{~h}$ after the shock, * $\mathrm{p}<0.05$; compared with that $2 \mathrm{~h}$ after IAH, ${ }^{,} \mathrm{p}<0.05$; compared with that in the sham-operated control group ${ }^{x} \mathbf{p}<0.01$.

treatment. In addition, in the sham-operated control group, no notable improvement in $\mathrm{pCO}_{2}$ increase caused by IAH was observed. However, there was no significant difference at 8 and 12 $\mathrm{h}$ after IAVI treatment between the sham-operated control group and IAVI group, but there was a significant difference at $12 \mathrm{~h}$ after IAVI treatment between the two groups.

$\mathrm{pO}_{2}$ showed a decreasing trend during IAH model establishment and was significantly decreased at $2 \mathrm{~h}$ after IAH compared with that before shock. The $\mathrm{pO}_{2}$ was significantly increased at 8 and $12 \mathrm{~h}$ after IAVI treatment $(\mathrm{p}<0.05)$, but there was no notable difference between 8 and $12 \mathrm{~h}$ after IAVI treatment. In the sham-operated control group, no notable improvement in the $\mathrm{pO}_{2}$ decrease caused by IAH was observed. There was no significant difference at 12 $\mathrm{h}$ after IAVI treatment between the sham-operated control group and IAVI group, while a significant difference at $8 \mathrm{~h}$ after IAVI treatment between the two groups was recorded $(p<0.05)$ (Tab. 1).

\section{Urinary bladder pressure}

When compared before shock and $1 \mathrm{~h}$ after shock, the urinary bladder pressure was significantly higher at $2 \mathrm{~h}$ after IAH
$(21.20 \pm 4.60 \mathrm{mmHg}$ vs $6.60 \pm 0.50 \mathrm{mmHg}$ and $21.20 \pm 4.60 \mathrm{mmHg}$ vs $7.70 \pm 0.60 \mathrm{mmHg}$, respectively; $<<0.05$ ). When compared with that $2 \mathrm{~h}$ after treatment, the urinary bladder pressure decreased significantly at 8,12 , and $22 \mathrm{~h}$ after treatment $(11.50 \pm 0.90 \mathrm{mmHg}$ vs $21.20 \pm 4.60 \mathrm{mmHg}, 10.40 \pm 0.99 \mathrm{mmHg}$ vs $21.2 \pm 4.60 \mathrm{mmHg}$, and $10 \pm 0.65 \mathrm{mmHg}$ vs $21.20 \pm 4.60 \mathrm{mmHg}$, respectively; $\mathrm{p}<0.05$ ). In the sham-operated control group, the urinary bladder pressure did not significantly change at $8 \mathrm{~h}, 12 \mathrm{~h}$ or $22 \mathrm{~h}$ after treatment compared with that $2 \mathrm{~h}$ after treatment $(26.5 \pm 2.00 \mathrm{mmHg}$ vs $21.20 \pm 4.60$ $\mathrm{mmHg} ; 28.00 \pm 1.50 \mathrm{mmHg}$ vs $21.2 \pm 4.60 \mathrm{mmHg} ; 27.3 \pm 0.96 \mathrm{mmHg}$ vs $21.2 \pm 4.60 \mathrm{mmHg}, \mathrm{p}>0.05$ ). In IAVI group, when compared with that measured $2 \mathrm{~h}$ after treatment, the urinary bladder pressure decreased significantly at $8 \mathrm{~h}, 12 \mathrm{~h}$ and $22 \mathrm{~h}$ after treatment $(11.50 \pm 0.90$ $\mathrm{mmHg}$ vs $21.20 \pm 4.60 \mathrm{mmHg} ; 10.40 \pm 0.99 \mathrm{mmHg}$ vs $21.2 \pm 4.60$ $\mathrm{mmHg} ; 10 \pm 0.65 \mathrm{mmHg}$ vs $21.20 \pm 4.60 \mathrm{mmHg} \mathrm{p}<0.05$ ), while compared with the sham-opearated control group, $\mathrm{p}<0.01$ (Fig. 3).

\section{Changes in diaphragm height and lung CT Hounsfield units}

All eight experimental animals showed no pleural effusion. Compared with that before shock (Fig. 4A), the diaphragm height was significantly higher $2 \mathrm{~h}$ after IAH $(-117.3 \pm 1.5 \mathrm{~mm}$ vs $-128.5 \pm 2.7 \mathrm{~mm}$, respectively; $\mathrm{p}<0.05$ ) (Fig. 4B). In the IAVI group, the diaphragm height (Fig. 4C) declined significantly at 22 $\mathrm{h}$ after treatment compared with that $2 \mathrm{~h}$ after IAH $(-126.3 \pm 1.4$ $\mathrm{mm}$ vs $-117.3 \pm 1.5 \mathrm{~mm}$, respectively; $\mathrm{p}<0.05$ ). Compared with the sham-operated control group at $22 \mathrm{~h}$ after treatment, the diaphragm height showed a significant change $(-126.3 \pm 1.4 \mathrm{~mm}$ vs $-117.9 \pm 0.9$ $\mathrm{mm}$, respectively; $\mathrm{p}<0.05)$. In the sham-operated control group, there was no significant difference at $22 \mathrm{~h}$ after treatment compared with that at $2 \mathrm{~h}$ after IAH $-117.9 \pm 0.9 \mathrm{~mm}$ vs $-117.3 \pm 1.5$ $\mathrm{mm}$, respectively; $\mathrm{p}>0.05$ ) (Fig. 5).

Compared to those before shock, the lung CT Hounsfield units increased significantly at $2 \mathrm{~h}$ after IAH $(-656.5 \pm 33.1 \mathrm{HU}$ vs $-704.5 \pm 21.0 \mathrm{HU}$, respectively; $\mathrm{p}<0.05$ ). In the IAVI group, the lung CT Hounsfield units decreased at $22 \mathrm{~h}$ after treatment compared with those $2 \mathrm{~h}$ after IAH while showing no significant difference $(-680.6 \pm 20.3 \mathrm{HU}$ vs $-656.5 \pm 33.1 \mathrm{HU}$, respectively; $\mathrm{p}>0.05$ ). No significant difference was found also in lung CT
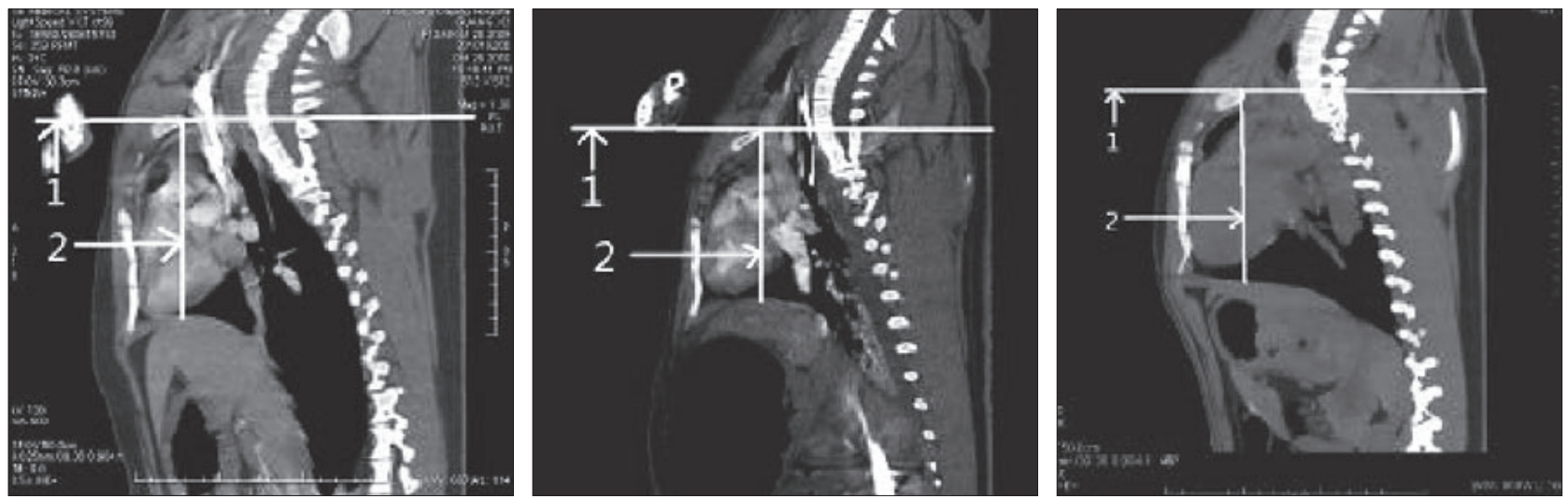

Fig. 4. Thoraco-abdominal CT examination was performed with minipigs in supine position before shock, $2 \mathrm{~h}$ after IAH, and $22 \mathrm{~h}$ after treatment. The horizontal line (Line 1) along the superior border of the manubrium was drawn as the baseline, while the vertical distance (Line 2) between the highest point of the diaphragm and the baseline was recorded as the relative height of the diaphragm. 


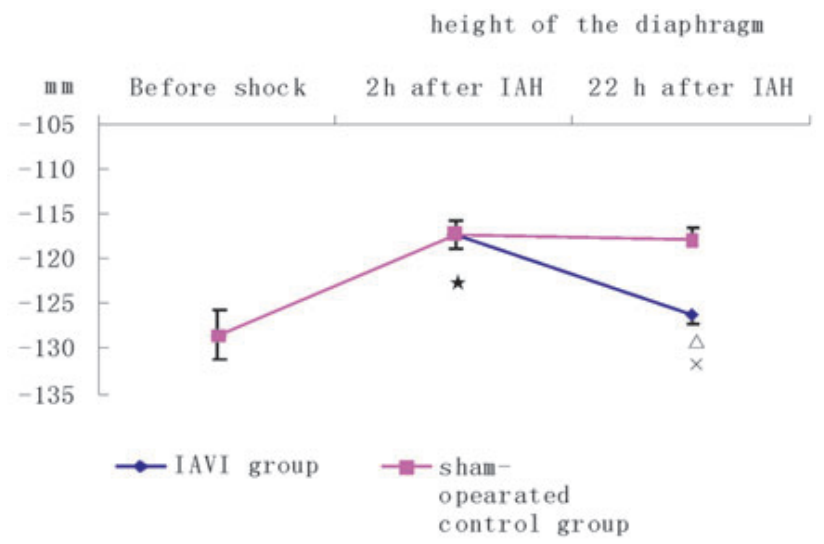

Fig. 5. The change in the relative height of the diaphragm (mean \pm SD) in different groups with IAH after hemorrhagic shock resuscitation. IAVI group $(n=4)$, sham-operated control group $(n=4)$. Compared with that before shock, * $p<0.05$. Compared with that in the sham-operated control group ${ }^{\Delta} p<0.05$. Compared with that $2 \mathrm{~h}$ after IAH, ${ }^{x} \mathrm{p}<0.05$.

Lung CT hounsfield units

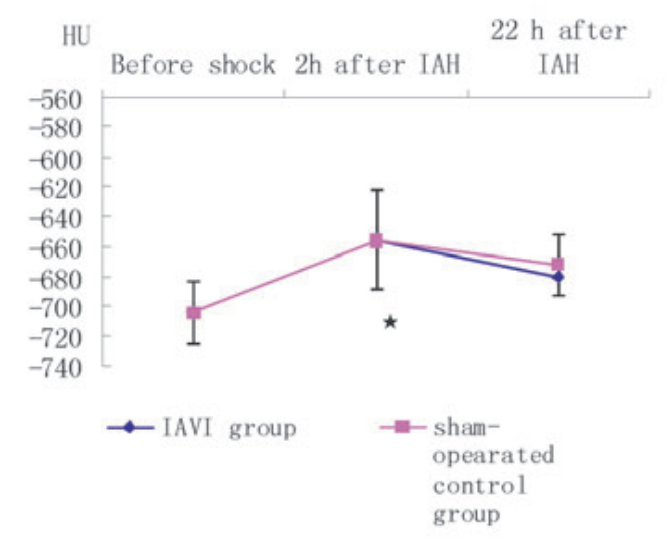

Fig. 6. The change in computed tomography value (mean \pm SD) in different IAH groups after hemorrhagic shock resuscitation. IAVI group $(n=4)$, sham-operated control group $(n=4)$. Compared with that before shock, * $\mathbf{p}<0.05$

Hounsfield units $22 \mathrm{~h}$ after treatment in IAVI group compared to the sham-operated control group ( $-680.6 \pm 20.3 \mathrm{HU}$ vs $-671.8 \pm 12.3$ HU, respectively; (Fig. 6).

\section{Gross pathological examination}

In the sham-operated control group, lung congestion and atelectasis were observed. Under light microscopy, interstitial edema and pulmonary congestion combined with alveolar infiltration with inflammatory cells were observed (Fig. 7A). In the IAVI group, pulmonary edema, congestion, and reduced inflammation were observed in lung tissues (Fig. 7B).

\section{Wet-to-dry ratio of lung weight}

The wet-to-dry ratio of lung weight in the IAVI group was significantly decreased compared with that in the sham-operated control group ( $4.15 \pm 0.76$ vs $5.68 \pm 0.35$, respectively; $p<0.05$ ).

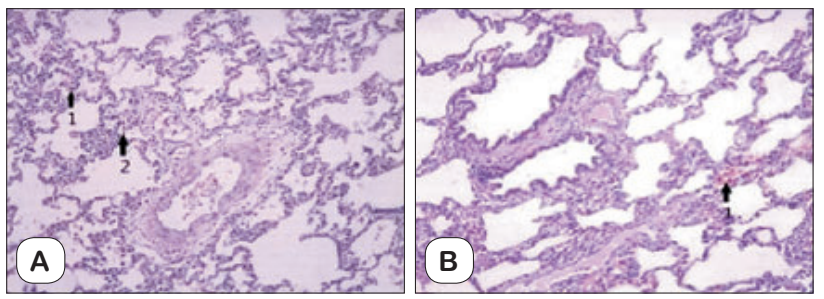

Fig. 7. Observation of right lung HE staining $(10 \times 20)$ : many red cells (arrow 1) and inflammatory cells (arrow 2) were observed in pulmonary alveolus and interstitium with obvious lung edema in the shamoperated control group (A), which improved in the IAVI group (B).

\section{Discussion}

An IAP exceeding $12 \mathrm{mmHg}$ is considered to be pathologically elevated and has been termed IAH. This condition can result from accumulation of peritoneal fluid, obstruction, pancreatitis, trauma, or abdominal bleeding, and may lead to ACS (15). When IAH is $>15 \mathrm{mmHg}$, an elevated hemidiaphragm can be seen on chest radiographs. (16) ACS can increase the volume of abdominal cavity by decompressive laparotomy, and decrease the abdominal contents by evacuating retained blood and removing the unnecessary packs (if present), thus decreasing the IAP. Vacuum sealing for temporary closure of the abdominal incision can avoid the intra-abdominal organ infection, control the abdominal secretion, prevent the loss of body fluid and body temperature, and maintain the abdominal fascia tension so as to achieve abdominal closure.

In this study, an IAH model was established through resuscitation with a large amount of liquid after hemorrhagic shock in minipigs in consistence with the report of Shah et al. This model simulated the twisting of the portal vein resulting from severe hemorrhagic shock after severe liver injury and perihepatic packing (17). When the bladder pressure increased by $14.6 \mathrm{mmHg}$ the remarkably impaired lung function was presenting as tachypnea, increased $\mathrm{paCO}_{2}$, and decreased $\mathrm{paO}_{2}$ (Tab. 1). Balogh et al reported that elevated bladder pressure was associated with a decrease in mixed venous oxygen saturation and $\mathrm{DO}_{2} \mathrm{I}$ and rise in the $\mathrm{paCO}_{2}$ level (18). Shah et al reported elevated peak inspiratory pressures and decreased $\mathrm{pAO}_{2}: \mathrm{FIO}_{2}$ ratios in ACS patients (17). Zhou et al also reported elevated peak inspiratory pressures, $\mathrm{paCO}_{2}$, and central venous pressures and decreased $\mathrm{pAO}_{2}: \mathrm{FIO}_{2}$ ratios (9). The horizontal line along the superior border of the manubrium was drawn as a baseline, while the vertical distance between the highest point of the diaphragm and the baseline was recorded as a relative height of the diaphragm, and CT values of the left lower lung were measured. Our method can more accurately reflect the compliance of the thorax compared with the method of evaluation of the diaphragm and the 10th thoracic vertebral body or above (19). In our experiment, the CT value indicated that the diaphragm height reached $11 \mathrm{~mm}$ relative to the elevated bladder pressure (Fig. 5), which was similar to the result of Ridings et al (20). In addition, we observed that the CT value of the lung increased by $48 \mathrm{HU}$ (Fig. 6), indicating that pulmonary interstitial edema was also a risky factor of lung dysfunction. This result was similar to the report by Zhou et al. stating that acute respiratory distress syndrome was secondary to increasing IAP (9). 
We observed that the changing $\mathrm{CT}$ values following hemorrhagic resuscitation and IAH were first observed in this animal experiment. We observed no remarkable pleural effusion, which was not a factor of lung function disorder in our experimental model.

Compared with that in the sham-operated control group, the lung function in the IAVI group showed a notable improvement with manifestations of relieved breathlessness, decreased $\mathrm{paCO}_{2}$, and increased $\mathrm{paO}_{2}$ at 8 and $12 \mathrm{~h}$ after the operation (Tab. 1). In addition, we observed that the bladder pressure in the IAVI group decreased by 9.7 and $10.8 \mathrm{mmHg}$ at 8 and $12 \mathrm{~h}$ after the operation, respectively;, compared with the preoperative values while the bladder pressure decreased by 15.0 and $17.5 \mathrm{mmHg}$ compared with that of the sham-operated control group (Fig. 3). Because of the difficulty in heavy-weight animal transportation, time arrangement of $\mathrm{CT}$ measurement, and management of other indicators during the experiment, we only performed CT examination at $22 \mathrm{~h}$ after the operation. At $22 \mathrm{~h}$ after the operation, the diaphragmatic height in the IAVI group decreased by $0.6 \mathrm{~mm}$ compared with that in the shamoperated control group (Fig. 5), and the lung CT value decreased by 24.1 and $8.8 \mathrm{HU}$ respectively; indicating no significance difference (Fig. 6), which was associated with the decrease in bladder pressure.

Furthermore, the pathological examination indicated that the wet-to-dry ratio of lungs in the IAVI group was notably decreased compared with that in the sham-operated control group, which is similar to the results reported by Shah et al (17). The pathophysiological examination also indicated an improvement in pulmonary interstitial edema and congestion. Our experiment proved that IAVI could significantly improve the lung function disorder following IAH. The possible mechanisms are as follows: (1) the decreased diaphragmatic height improved the lung ventilation volume or (2) pulmonary interstitial edema was relieved. The relatively fixed thoracic cavity volume, elevated diaphragm height, and decreased range of motion can lead to limited lung ventilation, increased functional residual capacity, disproportion of ventilation to blood ratio (21), decreased oxygenation, and carbon dioxide retention. Moreover, all the above-mentioned factors contribute to respiratory failure.

In summary, after IAH, lung dysfunction is largely caused by the rise of the diaphragm, retroperitoneal hematoma, and decline in lung compliance, etc. In addition to oxygen therapy and PEEP, the bladder pressure should be closely monitored, and IAVI should be performed should bladder pressure be persistently increased $(>20$ $\mathrm{mmHg}$ ) and routine respiratory support cannot improve the lung dysfunction. The reduction in IAP, decrease in diaphragm height, and restoration of the range of motion can fully relieve the lung dysfunction. However, because of the limitations in sample size and monitoring time, the long-term effects of IAVI surgery on lung function need be further examined.

\section{References}

1. Malbrain MLNG, Cheatham ML, Kirkpatrick A, Sugrue M, Parr $\mathbf{M}$, De Waele $\mathbf{J}$ et al. Results from the international conference of experts on intra-abdominal hypertension and abdominal compartment syndrome. Intens Care Med 2006; 32: 1722-1732.

2. Cheatham ML, Malbrain MLNG, Kirkpatrick A, Sugrue M, Parr M, De Waele $\mathbf{J}$ et al. Results from the International Conference of Experts on
Intra-Abdominal Hypertension and Abdominal Compartment Syndrome. II. Recommendations. Intense Care Med 2007; 33: 951-962.

3. Malbrain MLNG, Chiumello D, Pelosi P, Wilmer A, Brienza N, Malcangi $\mathbf{V}$ et al. Prevalence of intra-abdominal hypertension in critically ill patients: a multicentre epidemiological study. Intens Care Med 2004; 30: 822-829.

4. Sugrue M, Buhkari Y. Intra-Abdominal Pressure and Abdominal Compartment Syndrome in Acute General Surgery. World J Surg 2009; 33: 1123-1127.

5. Rizoli Sab, Mamtani Aab, Scarpelini Sabc, Kirkpatrick AWde. Abdominal compartment syndrome in trauma resuscitation.Curr Opin Anaesthesiol 2010; 23: 251-257.

6. Balogh Z, McKinley BA, Cox Jr CS, Allen SJ, Cocanour CS, Kozar RA et al. Abdominal compartment syndrome: the cause or effect of postinjury multiple organ failure. Shock 2003; 20: 483-492

7. Vegar-Brozovic V, Brezak J, Brozovic I. Intra-abdominal hypertension: pulmonary and cerebral complications. Transplantn Proc 2008; 40: 1190-1192.

8. Cheatham ML. Abdominal compartment syndrome: pathophysiology and definitions. Scand J Trauma Resusc Emerg Med 2009; 17: 10.

9. Zhou JC, Xu QP, Pan KH, Mao C, Jin CW. Effect of increased intraabdominal pressure and decompressive laparotomy on aerated lung volume distribution. J Zhejiang Univ Sci 2010; B 11: 378-385.

10. Malbrain ML, Pelosi P, De laet I, Lattuada M, Hedenstierna G. Lymphatic drainage between thorax and abdomen: please take good care of this well-performing machinery. Acta Clin Belg Suppl 2007; 1: 152-161.

11. Malbrain MLNG, De Iaet IE. Intra-Abdominal Hypertension: Evolving Concepts. Clin Chest Med 2009; 30: 45-70.

12. SUN S-J , ZHANG L-Y. Wound management of damage control laparotomy in trauma. Trauma Surg 2009; 11: 94-96

13. Malbrain MLNG, De Laet I, Van Regenmortel N, Schoonheydt K, Dits H. Can the abdominal perimeter be used as an accurate estimation of intra-abdominal pressure? Crit Care Med 2009; 37: 316-319.

14. Spencer P, Kinsman L, Fuzzard K. A critical care nurse's guide to intra abdominal hypertension and abdominal compartment syndrome. Austr Crit Care 2008; 21: 18-28

15. Scheppach W. Abdominal compartment syndrome. Best Pract Res Clin Gastroenterol 2009; 23: 25-33.

16. Vegar-Brozovic V, Stoic-Brezak J. Pathophysiology of Abdominal Compartment Syndrome. Transplant Proc 2006; 38: 833-835.

17. Shah SKDO, Jimenez FMS, Walker PAMD, Xue HMD, Uray KSP, Aroom KRMS et al. Cox CSJMD: A Novel Physiologic Model for the Study of Abdominal Compartment Syndrome (ACS). J Trauma Injury Infect Crit Care 2010; 68: 682-689.

18. Balogh Z, McKinley BA, Cocanour CS, Kozar RA, Cox CS, Moore FA. Patients with impending, abdominal compartment syndrome do not respond to early volume loading. Amer J Surg 2003; 186: 602-608.

19. Al-Bahrani AZ, Abid GH, Sahgal E, O'Shea S, Lee S, Ammori BJ. A prospective evaluation of CT features predictive of intra-abdominal hypertension and abdominal compartment syndrome in critically ill surgical patients. Clin Radiol 2007; 62: 676-682.

20. Davies J, Aghahoseini A, Crawford J, Alexander DJ. To close or not to close? Treatment of abdominal compartment syndrome by neuromuscular blockade without laparostomy. Ann Royal Coll Surg Engl 2010; 92: W8-9.

21. De Waele JJ, Hoste EAJ, Malbrain MLNG. Decompressive laparotomy for abdominal compartment syndrome - a critical analysis. Crit Care 2006; 10: R51.

Received March 31, 2012. Accepted January 23, 2013. 